\title{
VARENIUS E O CONHECIMENTO MATEMÁTICO DO SÉCULO XVII
}

\author{
Varenius and the mathematical knowledge \\ in the seventeenth century
}

Arlete de Jesus Brito ${ }^{1}$

Gert Schubring ${ }^{2}$

Resumo: Neste artigo, discutimos o contexto do desenvolvimento da Geografia que, no século XVII, liberou-se do seu papel nas diferentes fés cristãs, bem como a importância da cisão dos Protestantes, em Luteranos e Calvinistas, para o processo de secularização, e o conseguinte estabelecimento da Geografia como ciência moderna. Analisamos a contribuição fundamental do luterano Bernhard Varen, cuja obra Geografia Geral apresenta o paradigma dessa nova ciência. Naquela época, a Geografia era considerada um ramo da matemática, e esta obra nos dá indícios sobre notações e conceitos matemáticos utilizados naquele século. Analisamos, particularmente, o uso da notação decimal de números não inteiros e algumas aplicações de conceitos trigonométricos, comparando a edição original com as principais reedições desta obra.

Palavras-chave: História. Educação matemática. Notações matemáticas. Geografia. Ciência moderna.

\begin{abstract}
In this paper, we discuss the context of the development of geography until the seventeenth century when it became liberated from its function in the service of the different Christian faiths; we discuss the importance of the division of the Protestant confession into the Lutheran and the Reformed one for the process of secularization and for the establishment of geography as a modern science. We analyze the fundamental contribution by the Lutheran Bernhard Varen, whose volume General Geography constitutes the paradigm for this new science. In that time, Geography was considered to be a branch of mathematics, and this book offers us insights into both, mathematical notations and mathematical procedures. We analyze, in particular, the use of the decimal number notation for nonintegral numbers and also some applications of trigonometry, comparing the original edition with the major re-editions of this seminal work.
\end{abstract}

Keywords: History. Mathematical education. Mathematical notations. Geography. Modern science.

\footnotetext{
${ }^{1}$ Pós doutora em História e Educação Matemática. Docente, Licenciatura em Matemática, Universidade Estadual Paulista (Unesp). Rio Claro, SP. arlete@rc.unesp.br

${ }^{2}$ Livre docente em História da Matemática. Pesquisador do Instituto de Didática da Matemática, Universidade de Bielefeld. Bielefeld, Alemanha. gert.schubring@uni-bielefeld.de
}

\footnotetext{
${ }^{1}$ Departamento de Educação, IB, Unesp Av. 24A, 1515, Bela Vista

Rio Claro, SP, Brasil

$13.417-530$
} 
Brito, A. J.; Schubring, G.

\section{Introdução}

Bernhard Varen (1622-1650), conhecido também sob o seu nome latinizado Bernardus Varenius, é geralmente considerado na historiografia da geografia como "um dos maiores geógrafos de todas as épocas" (BECK, 1973, p. 113). Siegmund Günther, um historiador clássico da geografia, afirmou, no início do século XX, que: "Bernhard Varenius estabeleceu o primeiro sistema para o ensino da geografia geral que merece verdadeiramente este nome e ao mesmo tempo também sua correta designação que lhe tem assegurado, na ciência, um lugar duradouro" (GÜNTHER, 1904, p. 150).

Günther elogiou, também, a generalidade das abordagens feitas por aquele autor e sua habilidade em sintetizar particularidades. A Allgemeine Deutsche Biographie, obra clássica de biografia alemã, escolheu uma comparação ilustrativa: "Varenius criou uma dessas raras obras científicas que se erguem como uma cordilheira entre duas épocas" (ADB, 1895, p. 489).

Apesar de Varenius não ter sido o primeiro autor a realizar a distinção entre as duas partes da geografia, quais sejam, a universal e a particular - já que ela pode ser encontrada tanto na obra Systema Geographicum (1611) de Bartholomäus Keckermann (1573-1609) (CAPEL, 1974), quanto na de Paullus Merula (1558-1607), Cosmografiae libri tres ... (1605) - seu grande mérito foi o de ter introduzido, de modo sistemático, tal distinção, e, sobretudo, o de ter estabelecido a geografia como uma ciência moderna, embasando-a nos pressupostos da física moderna.

Além disto, é necessário ressaltar o processo definitivo de secularização da geografia que ocorreu a partir dessa obra, ou seja, a separação dos fins teológicos e a adoção exclusiva da matemática e dos métodos empíricos das ciências naturais. Esta secularização foi possível devido à Reforma, em particular com a cisão entre os luteranos e os calvinistas, que causou o rompimento dos elos tradicionais entre a geografia e a teologia.

O exemplo de Merula mostra que os tratados da geografia, desde a Idade Média, não distinguiam entre o saber confirmado pela experiência, pela observação, e o saber religioso transmitido pela Bíblia. A geografia servia a fins religiosos de confirmar a fé cristã e de apresentar a Terra e o mundo como criações de Deus. Fica evidente que, para a Igreja Católica, a geografia foi subordinada à teologia e que as afirmações nas obras geográficas deveriam estar de acordo com a Bíblia. Assim, a geografia foi identificada como a "cosmografia", na qual a Terra seria o centro do mundo.

Porém, não é pouco discutido o desenvolvimento da geografia desde a Reforma no protestantismo. É somente a partir dos anos 1970 que a história da geografia nesse período começou a ser investigada. Revelou-se que os protestantes, de início, utilizavam a geografia para fins religiosos, porém em direções divergentes, ou seja, os luteranos e os calvinistas desenvolveram doutrinas diferentes ${ }^{3}$. A causa das diferenças foi a concepção divergente da denominada "providência divina" (BÜTTNER, 1973).

\footnotetext{
${ }^{3}$ Deve-se ressaltar que as lutas teológicas entre os luteranos e os calvinistas foram, na época, tão agressivas quanto as contra os católicos.
} 
Zwingli (1484-1531), como representante do calvinismo, utilizou a geografia para a explicação da sua concepção de providência: ela deveria ilustrar a unidade entre a criação do mundo e a situação atual - o contínuo desde a criação, o dilúvio até a dominação de Deus sobre a natureza. Criação, dilúvio e reino atual do mundo seriam realizações do mesmo e único plano de Deus: da providência. Assim, os calvinistas baseavam a geografia sobre a Bíblia $e$ a natureza. Pelo contrário, Melanchthon (1497-1560), como representante dos luteranos, via como importante o governo atual de Deus sobre o mundo. Assim, ele explicava este governo com referência a fatos da geografia que supostamente mostravam o funcionamento da natureza sob o governo divino. Para os luteranos, não importariam tanto as ações anteriores de Deus; o primordial seria obter o Deus clemente. A consequência foi que os luteranos não precisavam da Bíblia para explicar a providência (BÜTTNER, 1973, p. 4, 118). Exemplos de autores de geografias no sentido calvinista foram Sebastiam Münster (1489-1552) e Gerhard Mercator (1512-1594); exemplos da direção luterana foram Caspar Peucer (1525-1602) e Michael Nean$\operatorname{der}(1525-1595){ }^{4}$

Vale sublinhar que o processo de secularização da geografia começou dentro das concepções protestantes. Como Büttner (1973) mostrou, foi o teólogo e geógrafo calvinista Keckermann que estabeleceu a base teológica para a laicização da geografia, por meio de uma nova concepção da providência e dos pecados: pelo pecado, a relação subjetiva do homem com Deus foi perturbada; então, o homem não é mais capaz de conhecer Deus. Mas na área objetiva de observação da natureza, conhecimento ("Erkenntnis") verdadeiro, o pecado não tem um efeito perturbador. Paralelamente a esta doutrina do pecado, Keckermann reorientou a doutrina da providência: segundo ele, o efeito da providência divina não mais constava na natureza - antes, é no homem, na área humana que se poderia observar e constatar a providência. Assim, a ciência da geografia poderia ser praticada independentemente da teologia (BÜTTNER, 1973, p. 5). Keckermann expôs sua concepção na obra Systema geographicum, publicada postumamente, já citada aqui. Esta obra tornou-se tradicional e, nela, o autor manteve e, pretensamente, demonstrou que a Terra ficaria imóvel no centro do universo.

Deve-se imaginar o clima político-científico desses anos. Apenas pouco tempo antes da publicação da Geografia Geral de Varenius, Galileu havia sido condenado pela Inquisição da Igreja Católica por ter mantido que a Terra não constitui o centro do universo (1633). Como conseqüência, Descartes não ousou publicar sua obra sobre o cosmo. Varenius também utilizou, com cuidado, o sistema copernicano em sua obra; no capítulo VI, De situ seu loco Telluris respectu Planetarum et Stellarum, ele considerou necessário um fundamento "superior" para o novo conceito dos copernicanos; assim, apresentou-o não como sendo novo, mas como mais antigo que o conceito dos ptolemaicos, pois afirma "os copernicanos colocam, de acordo com os antigos pitagóricos, o Sol no centro de todo o universo. A Terra constitui um planeta entre Marte e Vênus"5 (VARENIUS, 1650, p. 57).

\footnotetext{
${ }^{4}$ As concepções respectivas dos calvinistas e luteranos sobre a geografia são apresentadas em: Büttner (1973, p. 121-71).

5 "Copernicani vero cum antiquis Pythagoricis collocant Solem in centro omnium stellarum, Tellurem vero tanquam panetam inter Martem et Venerum constituunt” (VARENIUS, 1650, p. 57).
} 
Brito, A. J.; Schubring, G.

O que é observável e significativo é a ciência grega ser evocada como uma instância superior de decisão - um indicativo da secularização e, ao mesmo tempo, do humanismo. Um sinal impressionante de cuidado é a apresentação do argumento na forma discursiva: Varenius apresenta as razões dos ptolemaicos e, depois, as rebate utilizando as razões dos copernicanos (VARENIUS, 1650). Em outro ponto, que discute o movimento da Terra, a forma é a de disputa, da retórica tradicional, com proponentes contra oponentes: desta vez, Varenius apresenta oito razões dos copernicanos, depois as contra-razões dos ptolemaicos e, enfim, a refutação desses argumentos pelos copernicanos. No fim, Varenius evita atribuir o sistema copernicano como sendo a verdade, afirma somente que o sistema copernicano corresponde melhor às observações astronômicas: "o movimento que é atribuído a Terra, pelos copernicanos, cuja explicação se costuma aplicar na astronomia como sendo mais exata" (VARENIUS, 1650, p.55).

Newton, na tradução que realizou, em 1672, da obra de Varenius, não modificou esta apresentação cuidadosa do sistema copernicano. Foi somente na versão inglesa de 1712 e, depois, na francesa de 1755, que se mudou a argumentação: "Na parte astronômica, nós fortificamos os argumentos de nosso autor em favor da hipótese de Copérnico e corrigimos e esclarecemos proposições tiradas, por outros, de autores modernos ou reformuladas a partir de observações mais exatas, realizadas desde seu tempo"7 (VARENIUS, 1755, p. XIV).

Fica em aberto o problema sobre como, do lado católico, desenvolveu-se a concepção da geografia, em qual grau e intensidade se continuou a tradição dos tratados da esfera, e como e quando se teve acesso ao copernicanismo - primeiro como hipótese. Os tratados do padre Jose Zaragoza (1627-1679) na Espanha, por exemplo, o Cursus Mathematicus (1672-74) e o Esphera en común, celeste e terráquea (1675) afirmam, depois da obra de Varenius ser publicada e traduzida para outras línguas, que a Terra constituía o centro do mundo (CAPEL, 1980, p. 6).

A seguir, vamos apresentar uma breve biografia de Varenius, não tanto para expor fatos episódicos de sua vida, mas para observarmos a importância da educação luterana na composição de suas obras.

\section{Elementos da biografia ${ }^{8}$}

Lamentavelmente, pouco se sabe sobre a vida do Varenius e, em particular, os anos de seu nascimento e morte não são confirmados. É provável que sejam, respectivamente, $1622 \mathrm{e}$ 1650. Bernhard nasceu em Hitzacker, cidade em que na época residia o duque de Brauns-

\footnotetext{
6 "motus qui à Copernicanis Telluri ascribitur, cujus accuratior explicatio in Astronomia solet adhiberi" (VARENIUS, 1650, p. 55).

7 "Dans la partie astronomique, nous avons fortifié les argumens de notre auteur en faveur de l'hypothèse de Copernic, et nous avons corrigé et eclairci ces propositions par d'autres tirées des Auteurs modernes ou réformées sur des observations plus exactes, faites depuis son tems” (VARENIUS, 1755, p. xiv).

${ }^{8}$ Esta parte é basicamente baseada na obra de S. Günther, 1905.
} 
chweig-Lüneburg. O pai de Varenius, Heinrich, foi pastor da corte do duque. Com efeito, a família de Bernhard praticava a fé luterana e ele foi educado e estudou em contextos luteranos.

Depois de ter sido educado por ensino particular, Bernhard foi matriculado em abril de 1640 em Hamburgo, no Akademisches Gymnasium. Tais instituições ocupavam um papel intermediário entre a escola secundária e a universidade. Ofereciam lições de disciplinas universitárias, não somente da filosofia, mas também de direito, entre outras. $\mathrm{Na}$ época, o reitor do Gymnasium era Joachim Jungius (1587-1657), um sábio notável da época que se tornou amigo e conselheiro de Varenius.

Por causa da grande influencia exercida por Jungius sobre Varenius, vale a pena esboçar brevemente sua vida, em particular porque mostra características da vida acadêmica da época. Jungius foi educado em Lübeck e estudou filosofia e matemática na universidade de Rostock. Já em 1609, foi nomeado professor de matemática na universidade de Gießen e distinguiu-se em astronomia. Embora já fosse professor, considerou que sua formação não estava completa e foi para a Itália, para a universidade de Padova, estudar medicina. Uma característica das universidades da Itália do norte foi que o ensino das artes - e também da matemática - integravam a faculdade de medicina.

Assim, era comum que professores de matemática fossem para esta faculdade, com a finalidade de se tornarem professores de medicina (SCHUBRING, 2002). Ao retornar daquele país, Jungius alternou entre posições de professor de matemática e de professor de medicina. Ele mostrou-se um forte propagador do método empírico-experimental nas ciências e das abordagens de Francis Bacon. Em 1628, Jungius obteve, como posição definitiva, a de reitor do Johanneum, liceu renomado de Hamburgo, e do Akademisches Gymnasium, que constituía a classe selecta do liceu. Ele modernizou o ensino e foi particularmente ativo no fortalecimento da matemática, naquelas instituições.

Foi nessa última instituição, desde 1640 até 1643, com um programa de ensino cientifico e com uma didática moderna, para a época, que Varenius recebeu a sua formação, sendo essa a mais decisiva, e não na universidade de Königsberg, como relatado geralmente. Em Könisberg, ele estudou filosofia, matemática e medicina, mas devido à má qualidade das lições, um ano e meio depois, em 1645, mudou-se para Leiden, uma universidade holandesa muito renomada naquele período. De orientação calvinista, a universidade admitia, em particular, alunos alemães calvinistas, mas também estudantes luteranos. Em Leiden, Varenius continuou a estudar filosofia, matemática e medicina, e interessou-se, em particular, pelas seções cônicas ${ }^{9}$ e pelas obras de Apolônio. Sem ter obtido o título de médico, Varenius terminou os seus estudos, provavelmente em 1647, e mudou para Amsterdã a fim de ganhar a vida por meio do ensino particular e, assim, financiar a continuação de seus estudos. A guerra dos trinta anos na Alemanha (1618-1648), que não foi mais uma guerra entre exércitos, mas dizimou cidades e sua população civil, o afetou financeiramente, pois, pouco antes do fim da guerra, em 1646, a cidade de Ülzen, onde se localizava a residência da família, foi destruída e, com ela, também a casa de seus pais, de modo que Bernhard perdeu a herança.

\footnotetext{
${ }^{9}$ Segundo Capel (1974), Varenius teria elaborado um manuscrito, não publicado, sobre cônicas, intitulado De lineis curvis, imprimis de sectionibus conicis.
} 
Brito, A. J.; Schubring, G.

Tentativas de obter, em Amsterdã, uma posição como professor de matemática fracassaram, por causa da sua fé luterana não apreciada nessa cidade calvinista (BREUSING, 1880, p. 138). Em seguida, Varenius decidiu, por um lado, finalizar os seus estudos de medicina e, por outro, ganhar a vida compondo obras literárias. Este último fato está expresso na dedicatória de sua obra Geografia Geral aos cônsules de Amsterdã:

Primeiro, porque em toda a orbe da Terra não há cidade que mais necessite do conhecimento da Geografia que esta vossa, nem nenhuma que mais a utilize por suas admiráveis navegações a todos os rincões da Terra. Segundo, porque com as navegações de vossa gente, cresceu não pouco o estudo da Geografia [...]. Terceiro porque sei que sois protetores e promotores de toda a classe de investigações e, portanto, não duvido que considerareis também em alto grau o estudo geográfico. Motivo de louvor para vós é o fato de que benignamente favoreçais, alimentais e se esforçais em promover aos estudiosos [...], concedais também a mim [...] que possa louvar vossa generosidade. (VARENIUS, 1672, p. 13)

Para continuar seus estudos, Varenius voltou para Leiden e obteve aí, em junho de 1649, o grau de doutor em medicina. Ao que tudo indica, ele não chegou a trabalhar como médico. Pouco depois da apresentação de sua tese de doutorado em medicina, Disputatio de Febri in Genere, publicada em 1649, ele publicou duas obras sobre o Japão, uma sobre a geografia geral e a outra sobre as religiões. Um ano depois, em agosto de 1650, ele assinou o prefácio da sua Geografia Geral. É a ultima data certa de sua vida, pois parece que ele morreu no mesmo ano, bastante jovem. August Varenius (1620-1684), irmão de Bernhard, teve uma sorte melhor: tornou-se professor de hebraico e de teologia, na universidade de Rostock, e distinguiu-se por seus textos polêmicos contra a teologia calvinista.

\section{A nova concepção de geografia}

Não se sabe onde Varenius estudou geografia e quais fontes e materiais teve disponíveis. Segundo Capel (1974), sua amizade com o cartógrafo calvinista Joan Blaeu (1596-1673), membro do Conselho de Amsterdã, teria colaborado para Varenius escolher escrever o livro Geografia Geral. Entendemos que a situação econômica e política dos Países Baixos também colaborou para esta escolha, pois, desde o fim do século XVI, este país não somente se estabeleceu como um poder no comércio internacional, mas também como um poder colonial, primeiro abrindo acesso ao comércio com a Índia, pela Oost-Indische Compagnie, depois com as Américas, pela Westindische Compagnie, fundada em 1621, época em que os holandeses se fixaram no nordeste do Brasil (WÄTJEN, 1921). Embora a colônia no Brasil tenha se tornado um fracasso, depois da volta do príncipe Johann Moritz, em 1644, e, enfim, teve de ser abandonada, torrentes de informações geográficas, sobre a região, chegaram a Amsterdã, ou seja, havia, nos Países Baixos, uma grande riqueza de fontes sobre assuntos relacionados à geografia. 
$\mathrm{Na}$ geografia tradicional, dominavam ainda as concepções de Aristóteles, suas obras De coelo e Meteorologia. Sem uma geologia e sem uma física cientifica, não foi possível estabelecer a parte da geografia genuinamente das ciências físicas e naturais. Somente com esta parte desenvolvida, a geografia matemática, já existente tradicionalmente, pôde ligar-se produtivamente com a geografia física para constituir o que Varenius chamou de geografia particular, ou seja: "A que estuda a constituição de cada uma das regiões e tem, por sua vez, dois ramos: a corografia e a topologia. A corografia expõe a descrição de alguma região que tenha uma grande extensão e a topografia descreve com detalhe um lugar, ou extensão pequena da Terra" (VARENIUS, 1755, p. 3).

Como já mencionamos, uma das inovações da obra de Varenius consiste na introdução da distinção sistemática entre geografia geral, isto é, geografia universal, e a geografia particular, também denominada de especial. Segundo Varenius (1755), a Geografia Geral está dividida em três partes: a Absoluta, a Relativa e a Comparativa. A absoluta examinaria as propriedades da Terra, tais como: massa, forma, movimento etc. A relativa consideraria as propriedades como: latitude, zonas climáticas, estações do ano etc. A comparativa referia-se a propriedades deduzidas da comparação de diferentes lugares, como, por exemplo, a longitude. A Geografia Especial explicaria região por região considerando suas características, denominadas, por Varenius, de celestes, tais como altura do pólo, duração do dia etc; de terrestres, como os limites de territórios, suas dimensões, selvas e desertos etc, e de humanas, que seriam as características físicas e culturais dos habitantes de determinada região.

A distinção per se não foi inteiramente nova, como já afirmamos, pois existia em obras de precursores de Varenius. No livro do holandês Paullus Merula, já citado aqui, os termos "geographia generalis" e "geographia particularis" possuem um significado da geografia particular mais restrito que os dados por Varenius, além de lhes faltar a abordagem empíricocientifica. Suas fontes, utilizadas no Cosmografiae libri tres ..., incluem citações de autores gregos, de poetas, da bíblia, e se baseia nas opiniões das padres da Igreja e dos escolásticos (GÜNTHER, 1905). Por outro lado, a distinção feita por Keckermann, também já citado por nós, embasa-se na noção aristotélica de "ciência natural" (CAPEL, 1974).

A geografia foi entendida por Varenius como uma parte da matemática aplicada (ou mista). Segundo Capel (1980), as ciências matemáticas, no início da Idade Moderna, dividiamse em "puras" (como a geometria, aritmética, trigonometria e álgebra) e em "mistas", que consideravam não apenas a quantidade, mas também algum aspecto sensível e, por isto, eram consideradas físico-matemáticas. Entre estas últimas, estariam: a música, a mecânica, a óptica e a geografia.

\section{A representação de números não inteiros no livro Geografia Geral}

Em 511 páginas, divididas em três livros, o Geografia Geral apresenta conhecimentos relativos às dimensões, movimento e localização da Terra no sistema solar; à substância e constituição da Terra; a montanhas, florestas, desertos, atmosfera, ventos, águas minerais, lagos, rios e oceanos; à determinação de latitude e longitude; à cartografia e à arte de navegar. A matemática, como a entendemos hoje, tem lugar destacado em toda a obra, tanto no capítu- 
Brito, A. J.; Schubring, G.

lo II, todo ele dedicado a conhecimentos da geometria euclidiana, quanto em outros capítulos nos quais ela é utilizada em diversas aplicações. Em outro artigo (BRITO, 2006), realizamos uma análise aprofundada deste capítulo, denominado de Conbecimentos Geométricos Prévios. Aqui nos interessará observar, particularmente, as representações numéricas utilizadas nesta obra. Para isto, utilizaremos a edição de 1650, a de 1672, realizada em Cambridge, por Isaac Newton, e a de 1755, realizada na França, por Puisieux.

O sistema de numeração utilizado por Varenius é o decimal indo-arábico, que, na época, já estava completamente difundido pela Europa; porém, na obra aqui analisada, não há uniformidade nas representações numéricas de grandes números, pois, algumas vezes, se utiliza vírgula para separar as classes, e outras não, como, por exemplo, em "123,120,000" (VARENIUS, 1650, p. 39; 1672, p. 28) e “40958631512” (VARENIUS, 1650, p. 41; 1672, p. 28).

Não há, no Geografia Geral, nem na edição original de 1650, tampouco na edição publicada por Newton em 1672, a representação decimal de números não inteiros, nem mesmo o uso de frações decimais. Este fato é observável porque tanto Stevin (1548-1620), em sua obra De Thiende (O décimo), quanto Viète (1540-1603), no Universalium Inspectionum..., apêndice do Canon Mathematicus, já haviam recomendado o uso de frações decimais. No entanto, talvez isto não significasse que recomendavam o uso de frações cujo denominador fosse potência inteira de dez, mas apenas que tais representações não deveriam recorrer ao sistema de numeração sexagesimal. De fato, nas tabelas trigonométricas do Canon Mathematicus, são fornecidos os sinus totus, ou seja, valores trigonométricos que consideram um círculo cuja medida do raio é 100.000, e assim, evita-se o uso de números não inteiros para expressar valores do seno de um ângulo e de seu complementar, ou seja, do cosseno. Nesta tabela, encontramos, por exemplo, a seguinte sequência de números que expressam os valores de seno, cosseno, tangente, secante, cotangente e cossecante ${ }^{10}$, multiplicados por 100000 , do ângulo de $4^{\circ} 30^{\prime}$ :

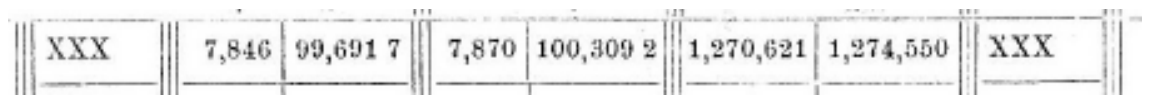

Figura 1. Viète (1579, p. Bij).

O numeral romano, segundo Hunrath (1899, p. 218), se refere à quantidade de minutos, na medida do ângulo. Os demais números são os valores trigonométricos aproximados, multiplicados por 100000, das funções acima discriminadas. Observem-se os numerais representados nas terceira e quinta colunas. Como a medida do raio é 100000, o algarismo sete, da terceira coluna, já não pertence mais à parte inteira do numeral que representa o sinus totus do ângulo de $85^{\circ} 30^{\prime}$. Porém não há nenhum símbolo, além da separação dos mesmos por um espaço, que indique que sete e dois estão na parte decimal não inteira dos numerais.

${ }^{10}$ Observe-se que os termos cosseno, cossecante e cotangente não são usados por Viète. 
Em nossas análises, atentamos para o fato de que Viète utiliza-se de dois tipos de notação quando pretende representar números decimais não inteiros, nestas tabelas. A primeira é a observada no parágrafo anterior. A outra está exemplificada na figura seguinte:

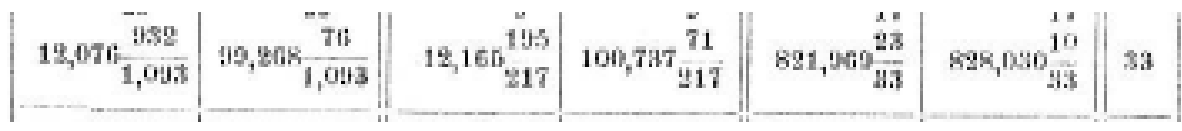

Figura 2. Viète (1579a, p. 44); Hunrath (1899, p. 223).

Nesta linha estão expressos aqueles valores trigonométricos, multiplicados por 100000 , para o ângulo de aproximadamente $6^{\circ} 56^{\prime}$. Em todos os números expressos nela, o próximo algarismo seria zero, pois em todas as frações o denominador é maior que o numerador. Nestes casos, ao invés de utilizar notação como a da Figura 1, Viète usa a notação fracionária.

Por outro lado, no trabalho La Statique, de Stevin (1987), bem como na edição feita desta obra por Girard em 1684, são utilizadas exclusivamente frações para representar números não inteiros - o que nos leva a concluir que, apesar daquelas recomendações inovadoras de Stevin e Viète, eles próprios não as utilizaram, geralmente, em suas obras, mas apenas em uma ou outra obra especializada, como no Universalium Inspectionum ... de Viète (1579b) e no De thiende, de Stevin (1965).

A representação fracionária de números racionais é utilizada, também, no Geografia Geral, porém não com denominadores que sejam potência inteira de dez, como podemos ler nos seguintes trechos: "A distância entre Amsterdã e Schoonhoven é de 9 1/4 " (VARENIUS, 1650, p. 36; 1672, p. 25). [...] "pela regra de ouro, 7 graus e 12 minutos estão para 1 grau, assim como 5000 está para 694 4/9 estádios” (VARENIUS, 1650, p. 37; 1672, p. 26). A passagem que nos parece mais interessante é aquela em que Varenius refere-se ao $\pi$. Nela afirma-se que o diâmetro está para a circunferência, assim “como 22 está para 7, ou como 31415926535 está para 1000000000" (VARENIUS, 1650, p. 12; 1672, p. 11). Newton manteve esta representação em sua edição do livro de Varenius e, em nenhuma passagem, o físico inglês utilizou a representação decimal de números não inteiros. Podemos inferir que Newton optou por manter as representações conforme a edição original, porém, também, em seus textos da época, publicados na Philosophical Transactions, Newton usou apenas frações de números inteiros no sistema de numeração decimal, como, por exemplo, no texto Apontamento sobre o telescópio catadioptral ${ }^{11}$ (1672); todavia, tais frações nunca têm o denominador igual a uma potência inteira de dez, o que confirma nossas observações anteriores acerca da notação decimal de números não inteiros.

A única passagem do Geografia Geral em que se utiliza o ponto para separar parte inteira e não inteira está em uma tabela em que a base utilizada não é dez, já que a terceira

\footnotetext{
${ }^{11}$ An account of a new catadioptrical telescope.
} 
Brito, A. J.; Schubring, G.

coluna relaciona milha e pés, e uma milha possui, segundo o livro analisado, 5280 pés. Nas quarta e quinta colunas, a base é a sessenta, já que a parte não inteira está dada em minutos.

Tabela de valor correspondente a $1^{0}$ sobre os paralelos (VARENIUS, 1650, p. 44-7; 1672 , p. $30-2)^{12}$.

\begin{tabular}{lccccccc}
\hline $\begin{array}{c}\text { Graus de distância } \\
\text { do equador ao paralelo }\end{array}$ & Pés em um grau & \multicolumn{2}{c}{$\begin{array}{c}\text { Milhas holandesas } \\
\text { Mill }\end{array}$} & pés & \multicolumn{2}{c}{ Milhas alemãs } & \multicolumn{2}{c}{ Milhas italianas } \\
\hline Equador & 28500 & 19. & & 15. & 0 & 60. \\
1 & 28496 & 18. & 1496 & 14. & 59 & 59. & 56 \\
2 & 28483 & 18. & 1483 & 14. & 55 & 59. & 55 \\
\hline
\end{tabular}

Porém, na edição de 1755, encontramos passagens em notas de rodapé que se utilizam de frações com denominadores que são potência inteira de 10, por exemplo, na mesma passagem citada acima, que trata do número p, há uma nota que afirma: "qualquer um sabe que a relação entre a circunferência do círculo e o diâmetro é incomensurável [...] mas não se apontou, nos números pequenos, uma que seja mais exata que a de André Metius, ou seja, de 113 para 355 que não se distancia mais que $\frac{3}{10000000}$ da verdadeira." ${ }^{13}$ (VARENIUS, 1755, p. 28).

Nossas observações sobre o uso da representação decimal de números não inteiros parecem contradizer Boyer quando afirma que

quando Viète as recomendou [as frações decimais] diretamente em 1579 elas já eram geralmente aceitas pelos matemáticos que se encontravam nas fronteiras da pesquisa [...] Stevin num círculo acima ou depois de cada dígito, ele escrevia a potência de dez assumida como divisor. Assim, o valor aproximado de p apareceria como 3 (0) 1(1) 4 (2) 1 (3) 6 (4). (BOYER, 1974, p. 232)

Na obra de Tropfke, especializada em história da matemática elementar, é afirmado que "desde cerca 1630, as frações decimais encontram-se geralmente nos manuais respectivos" (TROPFKE, 1980, p. 118), sem, no entanto, indicar exemplos de tais manuais. A nossa experiência, em particular com o Varenius, contradiz também esta afirmação.

A obra de Viète (1579), citada acima por Boyer, Canon Mathematicus ${ }^{14}$, é utilizada por Varenius em sua exposição sobre a trigonometria, na qual se refere, o tempo todo, ao valor dos

${ }^{12}$ Esta tabela inicia-se com $0^{\circ}$, ou seja, no Equador, e vai até $90^{\circ}$.

${ }^{13}$ Tal nota refere-se aos trabalhos de Metius (c. 1543 - c. 1620), engenheiro que viveu na Holanda, e, entre outros estudos, desenvolveu o valor de pi acima citado.

${ }^{14} \mathrm{Na}$ verdade, a referência do Boyer não é exata: O Canon Mathematicus contém somente tabelas e nada de textos em linguagem corrente. A advertência de Viète de não utilizar sexagesimais e o aviso de servir-se dos decimais fica, no entanto, na obra separada Universalium Inspectionum, também de 1579, p. 17. 
senos, tangentes e secantes como números inteiros, ou seja, ao sinus totus, como eram apresentados no texto de Viète. Em sua exposição ao leitor sobre como resolver problemas que envolvem estes conceitos trigonométricos, Varenius afirma que os resultados devem ser divididos por potências inteiras de dez, sem explicar o porquê desta divisão. Vejamos alguns exemplos, mas, antes, vamos verificar as definições de conceitos trigonométricos encontradas no Geografia Geral, que, segundo Varenius, são de uma utilidade singular nas ciências matemáticas e físicas, daí por que seu "desejo de dar algumas idéias destas coisas aos jovens geógrafos" (VARENIUS, 1672, p. 12).

Segundo nosso autor, "Seno de um arco é uma reta que passa por um dos extremos do arco, e é traçada perpendicularmente ao diâmetro que passa pelo outro extremo do arco". (VARENIUS, 1672, p. 11). Nenhuma figura acompanha esta definição. Nossa interpretação da mesma é a seguinte:

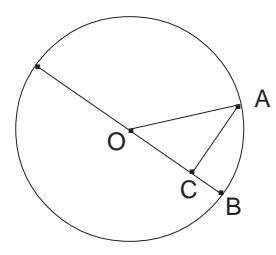

A medida AC seria o valor do seno do arco AB.

Segundo Varenius, tangente de um arco seria "uma reta que tangencia em uma das extremidades do arco e termina na reta que passa pelo centro e pelo outro extremo. Esta traçada por último é a secante do arco" (VARENIUS, 1672, p. 11). É interessante notar aqui a não diferenciação entre segmento de reta, um ente geométrico, e a medida deste segmento, que é um número. Novamente, nenhuma figura é fornecida, nossa interpretação é a seguinte:

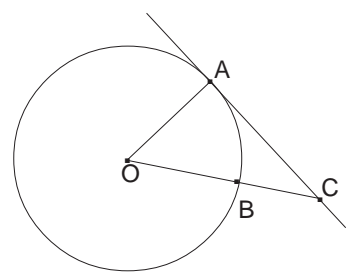

Podemos interpretar tais definições do seguinte modo: a tangente do arco AB seria AC, pois no triângulo retângulo $\mathrm{CAO}$, considerando o raio unitário, teremos:

$\operatorname{tg} C \hat{O} A=$ AC, enquanto a secante seria: $\sec C \hat{O} A=$ OC.

Observe-se que o autor não se refere a cosseno em nenhum momento de sua obra, mas apenas, em algumas passagens, ao seno do ângulo complementar - como, por exemplo, na página 12, quando trata de problemas trigonométricos, ou em outras, utiliza o inverso da secante; como, na página 61, quando explica um processo de determinação de altura de montanhas. O termo "co-sinus" foi sugerido pelo professor de astronomia em Londres, Edmund Gunter (1581-1626), em sua obra Canon Triangulorum (SMITH, 1958, p. 394). Viéte, no Canon Mathematicus, para referir-se ao cosseno utilizava o termo "sinus residuae". 
Brito, A. J.; Schubring, G.

Vejamos, agora, um exemplo no qual Varenius recorre à trigonometria para explicar como resolver um dos problemas que os geógrafos da época encontravam no exercício de sua profissão. No capítulo Sobre as Montanhas em Geral, Bernhard expõe como determinar a altura de uma montanha utilizando o altímetro:

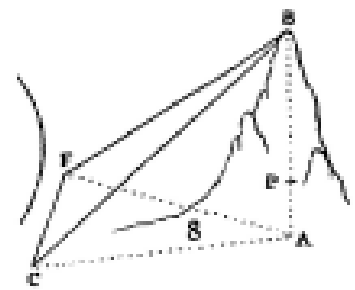

Figura 8. Varenius (1672), lâmina com figuras do livro I, sem numeração.

Fig. 8. Seja AB a altura de uma montanha, cujo pé seja A e o cume, B. Pegue uma linha FC, conveniente, de modo que os ângulos AFC e $\mathrm{ACF}$ sejam agudos e iguais. Observe os ângulos $\mathrm{BFC}$ e $\mathrm{BCF}$ e subtraia a soma destes ângulos de $180^{\circ}$, o resto será CBF. A seguir, meça CF e diga o seno do ângulo FBC está para o seno do ângulo $\mathrm{CFB}$, assim como FC está para BC, a distância da montanha a C. A seguir, coloque o instrumento em $\mathrm{C}$ e meça o ângulo BCA. Como o triângulo CBA é retângulo, $\mathrm{BAC}$ é reto, 90 gr., logo é dado o ângulo $\mathrm{ABC}$. Faça, no triângulo BCA, 10000000 está para o seno todo, assim como a distância $\mathrm{BC}$ está para a altura perpendicular do monte $\mathrm{AB}$.

Observamos que é utilizado o "sinus totus" do Canon Mathematicus, e se diz ao leitor que efetue a razão deste número por 10000000, no entanto, não se explica o porquê desta divisão. A questão que nos fica é como o leitor representava o resultado desta divisão?

Nessas passagens fica caracterizado o estado embrionário do desenvolvimento da noção de função, já que Varenius concebeu o seno, cosseno etc. sempre como linhas trigonométricas, e não como funções trigonométricas. Ao construir essas linhas sempre a partir de triângulos retângulos particulares, sempre obtinha valores positivos. Em toda a obra, não se encontram valores negativos, embora o uso de números negativos, nesta época, já fosse difundido na matemática (SCHUBRING, 2005, p. 45.). Talvez isto se deva ao fato de que as aplicações da matemática, realizadas no livro, não necessitassem deste conjunto numérico.

Na obra Geografia Geral, algo notável nas utilizações da matemática é o uso recorrente das proporções, denominadas, por Varenius, de "regra de três" ou de "regra de ouro". Embora as proporções, nesses contextos, apareçam segundo o entendimento matemático atual, como equivalência de frações, ou seja, pelo enfoque estritamente aritmético, nas obras contemporâneas as proporções eram utilizadas, também, pelo enfoque geométrico, por causa do domínio do paradigma geométrico encontrado, por exemplo, no livro Geometrie de Descartes (1596-1650). A separação entre geometria e álgebra não havia ocorrido. 


\section{Considerações finais}

Ao contrário da Alemanha, devastada pela guerra das religiões, os Países Baixos ofereceram ao luterano Varenius um clima de relativa tolerância religiosa, permitindo-o, assim, realizar uma simbiose pessoal entre as direções luterana e calvinista na ciência geográfica. A riqueza econômica desse país, devido ao seu comércio internacional e às atividades coloniais, juntamente com o espírito de vontade de descobertas, criavam uma abertura intelectual, e parece ter sido uma das primeiras realizações do que Max Weber, posteriormente, chamou de "ética protestante", que, segundo a hipótese de Robert Merton (Feldhay, Elkana, 1989), foi uma das bases das grandes revoluções científicas.

Varenius apresenta, então, num sentido duplo, uma exemplificação do quadro do desenvolvimento da ciência entre revolução e ciência "normal”, como concebido por Thomas Kuhn. Segundo Kuhn (1992, p. 30), o estudo dos paradigmas é o que "prepara basicamente o estudante para ser membro de determinada comunidade científica na qual atuará mais tarde". Assim, como geógrafo, Varenius foi um inovador, ao radicalizar a secularização da geografia, que já estava preparada nas direções luteranas e calvinistas; ao separar a Geografia da Teologia, e ao incorporar, em seu texto Geografia Geral, as últimas inovações relativas à física, astronomia e cartografia, como, por exemplo, as teorias copernicanas e a física de Descartes. Além disto, Bernhard indica, em seu livro, uma constante preocupação com a história da ciência - e aqui não sabemos se isto seria ou não uma inovação, na época. Pesquisas necessitam ser feitas sobre tal assunto.

Por outro lado, no que se refere ao conhecimento matemático, podemos considerá-lo como um "cientista normal", no sentido empregado por Kuhn ${ }^{15}$ (1992), e, por isto mesmo, seus textos nos possibilitam analisar os conhecimentos e representações matemáticas utilizados e difundidos, no século XVII, pela maioria dos cientistas da época. Como conhecimento paradigmático, temos mostrado o uso de números multiplicados por potências de dez a fim de evitar números não inteiros e, em particular, números decimais. É bastante característico que Newton, na sua edição da obra de Varenius, não tenha considerado ser necessário mudar essa prática, mantendo a maneira de Varenius de representar tais números. Outros exemplos, como o de evitar valores negativos, ao operar com linhas trigonométricas, e o uso de proporções para fins aritméticos, confirmam a "normalidade" de Varenius na área matemática e a sua qualidade para revelar o que foi normal na prática matemática da época.

\footnotetext{
${ }^{15}$ Segundo Kuhn (1992), mesmo nas ciências matemáticas existem problemas teóricos relacionados com a articulação de paradigma.
} 
Brito, A. J.; Schubring, G.

\section{Referências}

ADB. Allgemeine Deutsche Biographie. Verbete "Varenius", v. 39, p. 487-90, 1895.

BECK, H. Geographie: europäische Entwicklung in Texten und Erläuterungen. Freiburg: Alber, 1973.

BOYER, C. B. História da Matemática. São Paulo: Edgard Blucher, 1974.

BREUSING, A. Lebensnachrichten von Bernhard Varenius. Petermann's Mittheilungen aus Justus Perthes' Geographischer Anstalt, n. 26, p. 136-41, 1880.

BRITO, A. J. O estudo de um manual de ensino de matemática: o livro Geografia Geral. In: SEMINÁRIO INTERNACIONAL DE PESQUISA EM EDUCAÇÃO MATEMÁTICA, 3., 2006, Águas de Lindóia. Anais... Águas de Lindóia: SBEM, 2006.

BÜTTNER, M. Die Geographia generalis vor Varenius. Wiesbaden: Steiner, 1973.

CAPEL, H. La Geografia como ciencia matematica mixta: la aportacion del circulo jesuitico madrileño en el siglo XVII. Geocrítica, Barcelona, v. 5, n. 30, 1980. 1974.

. Varenio: Geografia general. Barcelona: Ediciones de la Universidad de Barcelona,

DESCARTES, R. The geometry of Rene Descartes with a facsímile of the first edition. Nova York: Dover Publications, 1954.

FELDHAY, R.; ELKANA, Y. (Eds.). 'After Merton': protestant and catholic science in seventeenth-century europe. Science in Context, Cambridge, NY, v. 3, n. 1, 1989.

GÜNTHER, S. Varenius. Leipzig: Thomas, 1905.

Geschichte der Erdkunde. Leipzig: Deuticke, 1904.

HUNRATH, K. H. Des Rheticus Canon Doctrinae Triangulorum und Vieta's Canon Mathematicus. Leipzig: B. G. Teubner, 1899. p. 215-40.

KUHN, T. S. A estrutura das revoluções científicas. São Paulo: Perspectiva, 1992.

SCHUBRING, G. Conflicts between generalization, rigor and intuition: number concepts underlying the development of analysis in 17 - 19th century France and Germany. New York: Springer, 2005

. Aspetti istituzionali della matematica: Storia della scienza. In: PETRUCCIOLI, S.

(Ed.). L'Etá dei Lumi. Roma: Istituto dell'Enciclopedia Italiana, 2002. p. 366-80. v. 6.

SMITH, D. E. History of mathematics. Nova York: Dover Publications, 1958. v. 1.

STEVIN, S. L' art pondéraire ou de la statique. Paris: A. C. L. Editions, 1987.

.; GERICKE, H.; VOGEL, K. De thiende. Frankfurt a.M.: Akad. Verl.-Ges., 1965.

TROPFKE, J. Geschichte der Elementarmathematik. Berlin/New York: Walter de Gruyter, 1980. v. 1. 
VARENIUS, B. Géographie générale.Paris: Vincent; Lottin, 1755.

Geographia generalis. Cantabrigiæ: Dickinson, 1672.

Geographia generalis. Amstelodami: Apud Ludovicum Elzevirium, 1650.

VIÈTE, F. Canon Mathematicus, seu ad triangula. Paris: Jean Mettayer, 1579.

Canonion Triangulorum [apêndica ao Canon mathem.]. In:

Canon

Mathematicus, seu ad triangula. Paris: Jean Mettayer, 1579a.

Universalium Inspectionum ad Canonem mathematicum. In:

Canon

Mathematicus, seu ad triangula. Paris: Jean Mettayer, 1579b.

WÄTJEN, H. Das holländische Kolonialreich in Brasilien: ein Kapitel aus der

Kolonialgeschichte des 17. Jahrhunderts. Gotha: Perthes, 1921.

Artigo recebido em fevereiro de 2008 e aceito em abril de 2008 